\title{
Influence of Heat Treatment on Mechanical Properties of DLC Deposited by FIB-CVD*
}

\author{
Naomichi SAKAMOTO**, Yasuo KOGO***, Takuya YASUNO**, \\ Jun TANIGUCHI*** and Iwao MIYAMOTO***
}

\begin{abstract}
The influence of heat treatment on the mechanical properties of DLC deposited by FIBCVD was examined. To evaluate the mechanical properties, Young's modulus and Vickers hardness were measured by the nano indentation tester. For the characterization of DLC structure, Raman scattering was used. The microstructures of samples were characterized by HRTEM equipped with EELS. From results of the indentation experiments, it was found that Young's modulus and Vickers hardness decreased with increasing heat treatment temperature. Analysis of Raman and EELS spectra indicated that the decrease of Young's modulus and hardness was caused by the decrease of $s p^{3}$ fraction.
\end{abstract}

Key Words: Diamond-Like Carbon, Focused Ion Beam, Chemical Vapor Deposition, Heat Treatments, Mechanical Properties, Raman Spectroscopy, High-Resolution Transmission Electron Microscopy

\section{Introduction}

Diamond-like carbon (DLC) is of great interest due to superior properties as a coating material, e.g., high hardness, high wear resistant, very low roughness, chemical stability and high transparency. In many area of engineering applications, DLC have found as coatings for cutting tools, hard disks, metal molds and optical windows ${ }^{(1),(2)}$. Therefore, production of DLC has been investigated by a number of different methods such as vacuum evaporation $^{(3)}$, laser ablation ${ }^{(4),(5)}$, magnetron sputtering ${ }^{(6)-(8)}$, chemical vapor deposition methods ${ }^{(9)}-(11)$.

Recently, focused ion beam assisted CVD (FIBCVD) method is developed as a new technique for producing of micro- and/or nano- DLC structures. In this method, scanning of focused ion beam leads to deposition of DLC at arbitrary nano-scale area. This technique realizes fabrication of three dimensional structures, which formed complex shape with overhung, hollow and bridging structures ${ }^{(12)}$. Therefore, the FIB-CVD is expected to be useful method for application to micro- and/or nanoelectromechanical system and other fields. Actually, R.

* Received 22nd May, 2005 (No. 05-4106)

** College of Science and Technology, Iwaki Meisei University, 5-5-1 Chuodai-Iino, Iwaki 970-8551, Japan. E-mail: sakamoto@iwakimu.ac.jp

*** Faculty of Industrial Science and Technology, Tokyo University of Science, 2641 Yamazaki, Noda 278-8510, Japan
Kometani et al. reported fabricating nanomanipulator and actuator $^{(13)}$, and T. Hoshino et al. demonstrated performance of FIB-CVD method by fabricating a moth's eyelike structure and a morpho butterfly-like structure with using this method ${ }^{(14)}$.

In view of practical application of the technology, it is important to understand influence of heat treatment on the mechanical properties and microstructures of DLC deposited by FIB-CVD. The influence, however, is not clear adequately. In this study, therefore, influence of the heat treatment was examined in detail. Furthermore, a relationship between the mechanical properties and microstructures was investigated.

\section{Experiments}

\subsection{Production and heat treatment of DLC}

The DLC was deposited by the FIB system (JEOL JFIB-2300) with an irradiation apparatus of a $\mathrm{Ga}^{+}$ion beam operating with $30 \mathrm{kV}$. For $\mathrm{Ga}^{+}$ion beam irradiation, extraction bias, emitter current, filament heat power and diameter of aperture were fixed $5.5 \mathrm{kV}, 1.35 \mu \mathrm{A}, 1 \mathrm{~W}$ and $0.5 \mathrm{~mm}$, respectively. Under this condition, ion beam current was $0.6-0.8 \mu \mathrm{A}$. The FIB-CVD was carried out by using phenanthrene $\left(\mathrm{C}_{14} \mathrm{H}_{10}\right)$ powder heated at $348 \mathrm{~K}$ as the source gas. The DLC was deposited on $\mathrm{Si}(100)$ substrate without heating. Produced DLC samples were heat treated in the range from 373 to $1573 \mathrm{~K}$ in Ar gas atmosphere. For the heat treatment experiments, heating and 
cooling rate were $0.05 \mathrm{~K} / \mathrm{s}$ and samples were kept at given temperatures for $1.2 \times 10^{3} \mathrm{~s}$.

\subsection{Evaluation of mechanical properties}

To evaluate the mechanical properties, Young's modulus and Vickers hardness were measured by a nano indentation tester (CMS Instruments Nano hardness tester). A Berkovich diamond pyramid was used as the indenter. Measurements were made by increasing the loading force with a load rate of $4 \mathrm{mN} / \mathrm{min}$, to a maximum force of $2 \mathrm{mN}$, followed by decreasing the loading force with the same rate.

\subsection{Characterization of structure by Raman spec- troscopy}

Various characterization methods have been used to determine the structural parameter. Raman scattering is a very popular tool for the structural characterization of DLC. For the study of the heat treatment influence on the structural properties of the DLC samples, Raman spectroscopy has been performed. The measurements were carried out using RAMANNOR-T64000 JOBIN YVON with $\mathrm{Ar}^{+}$laser. The laser output of $0.6 \mathrm{~W}$ was used.

\subsection{Analysis of microstructure and $s p^{3}$ fraction}

The microstructures of the DLC samples were characterized by high-resolution transmission electron microscopy (HRTEM; FEI Tecnai 30 S-Twin) operated at $300 \mathrm{kV}$. Cross-sectional HRTEM samples were prepared by using environmental scanning electron microscopy (ESEM; FEI Quanta 3D) or focused ion beam system (Hitachi FB-2100) equipped with micro-sampling systems. To investigate crystallographic structure of the DLC, HRTEM images were observed and convergent electron beam diffraction images were obtained. Moreover, electron energy loss spectroscopy (EELS) spectra were measured in order to estimate $s p^{3}$ fraction in the $\operatorname{DLC}^{(15)-(17)}$.

\section{Results and Discussion}

\subsection{The influence of heat treatment on mechanical properties}

Figure 1 shows load-displacement curves for the asdeposited and heat treated DLC samples at 673, 773 and $1573 \mathrm{~K}$. These samples show similar curve, while the displacement tends to increase with increasing heat treatment temperature. In addition, it is found that the slope of curve decreases with heat treatment temperature.

Young's modulus and Vickers hardness calculated from the load-displacement curves are shown in Fig. 2. With increasing heat treatment temperature, Young's modulus first decreases gradually, and decreases rapidly near $673 \mathrm{~K}$, then decreases gradually again. On the other hand, the variation of Vickers hardness against to heat treatment temperature is slightly different to Young's modulus. The hardness reminds fairly constant until $673 \mathrm{~K}$. Over $673 \mathrm{~K}$, Vickers hardness decreases with increasing heat treatment

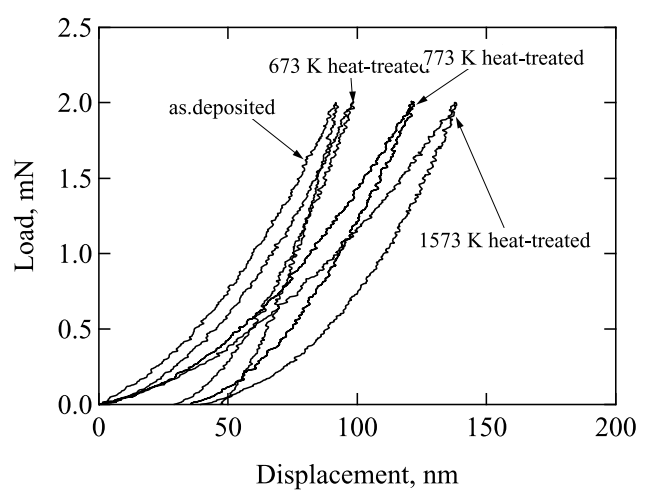

Fig. 1 Typical load-displacement curves for the as-deposited DLC sample and three heat treated DLC samples at 673, 773 and $1573 \mathrm{~K}$

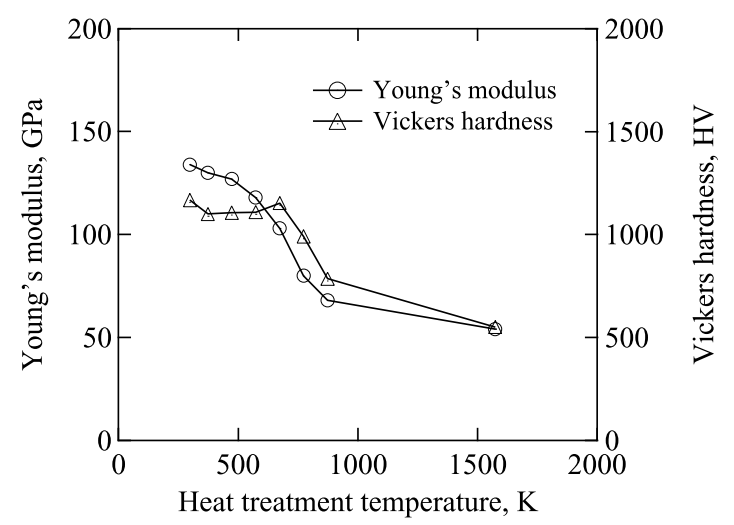

Fig. 2 Variations of Young's modulus (open circle) and Vickers hardness (open triangle) as a function of heat treatment temperature

temperature as well as Young's modulus. For the heat treated DLC produced by FIB-CVD, therefore, it was obvious that the heat treatment increased the displacement, while decreased Young's modulus and Vickers hardness.

\subsection{The variation of Raman spectroscopy due to heat treatment}

The visible Raman spectra of the DLC exhibit two broad peaks ${ }^{(3),(18),(19)}$. The first peak, commonly labeled $\mathrm{G}$ (graphite), is located at around $1580 \mathrm{~cm}^{-1}$ due to inplain vibration of the graphite-like rings. The second peak, labeled D (disorder), is located around $1330 \mathrm{~cm}^{-1}$ which results from the formation of ordered $s p^{2}$ cluster. Thus, the G-peak occurs in crystalline graphite, while D-peak occurs in many disordered graphitic materials. The Raman spectra are shown in Fig. 3 for all DLC samples. These spectra imply that a structural change occurs with heat treatment.

To determine the position and intensity of the G- and D-peaks, the Raman spectra were fitted two Gaussian distribution, centered at $\sim 1580$ and $\sim 1330 \mathrm{~cm}^{-1}$. The Gpeak position and the $I(\mathrm{D}) / I(\mathrm{G})$ ratio obtained from these Raman spectra are shown in Fig. 4, where $I(\mathrm{D})$ and $I(\mathrm{G})$ were intensity of D- and G-peak, respectively. The behav- 


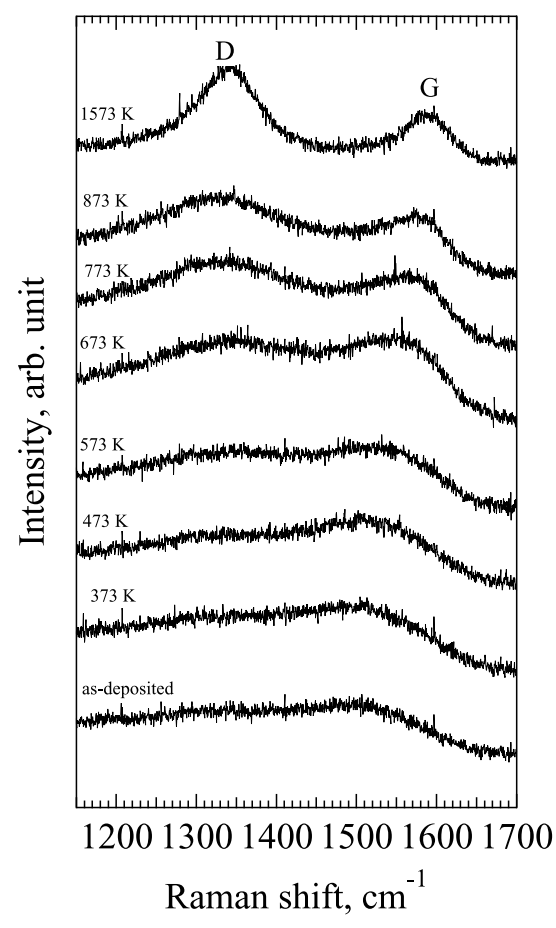

Fig. 3 Raman spectra of the DLC samples obtained at different heat treatment temperature

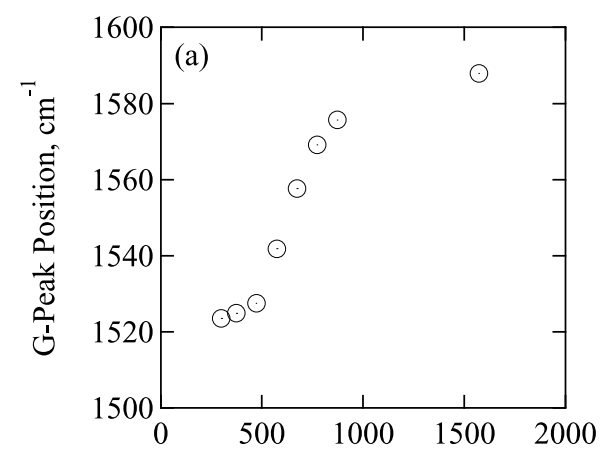

Heat-Treatment Temperature, $\mathrm{K}$

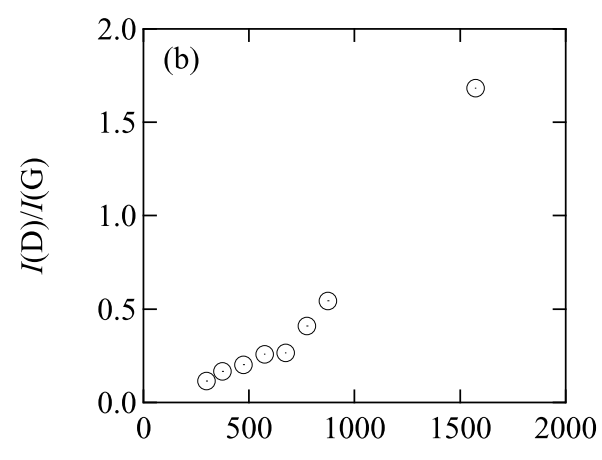

Heat-Treatment Temperature, $\mathrm{K}$

Fig. 4 (a) Position of Raman G-peak, and (b) intensity ratio of the $I(\mathrm{D}) / I(\mathrm{G})$ as a function of heat treatment temperature

iors of the G-peak position and the $I(\mathrm{D}) / I(\mathrm{G})$ ratio give imformation on the chemical bonding of the DLC. Ferrari et al. ${ }^{(19)}$ reported that Raman spectra of all disordered car-
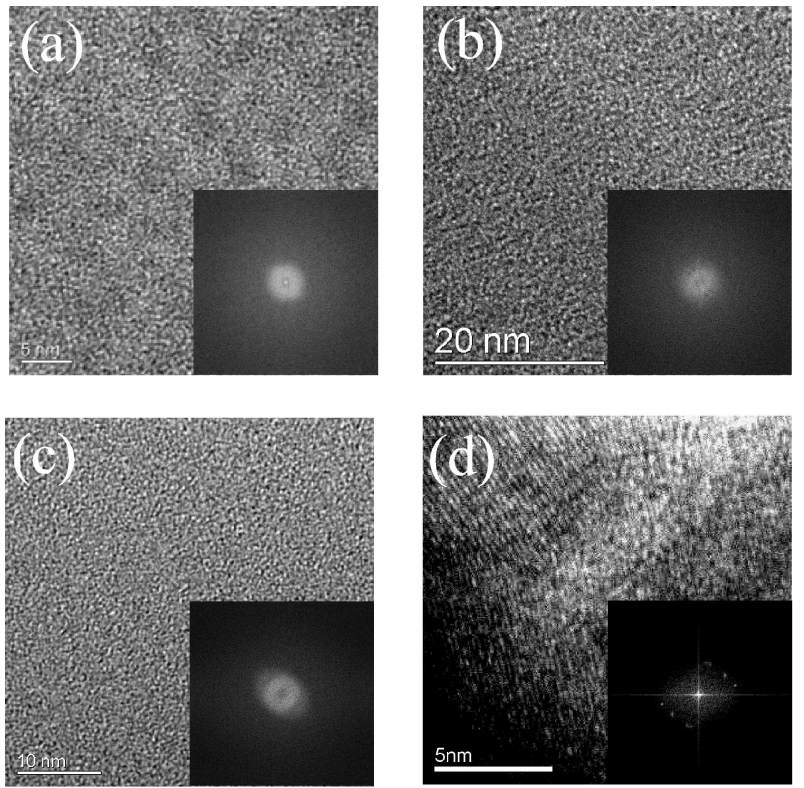

Fig. 5 HRTEM and convergent diffraction images for (a) asdeposited, heat treated samples at (b) $673 \mathrm{~K}$, (c) $873 \mathrm{~K}$ and (d) $1573 \mathrm{~K}$

bon were classified into three-stage by disordering process of carbon network. In one of the stages corresponding to disordering of a nano-crystalline graphite and loss of aromatic bonding, G-peak position shifts lower wave number and $I(\mathrm{D}) / I(\mathrm{G})$ ratio decreases owing to reduction of cluster size of the $s p^{2}-\mathrm{C}$ rings and the number of clusters. In Fig. 4, the G-peak position shifts higher wave number and the $I(\mathrm{D}) / I(\mathrm{G})$ ratio increases with increasing heat treatment temperature. This behavior seems to be caused by increases of cluster size and the number of $s p^{2}$ fractions.

\subsection{Microstructures and $s p^{3}$ fraction}

Figure 5 (a) - (c) and (d) show HRTEM and convergent diffraction images for as-deposited and heat treated samples at $673 \mathrm{~K}, 873 \mathrm{~K}$ and $1573 \mathrm{~K}$, respectively. For the DLC samples heat treated bellow $873 \mathrm{~K}$ (Fig. 5 (b) and (c)), HRTEM images and convergence electron diffraction images reveal that the DLC has amorphous structures as as-deposited sample (Fig. 5(a)). Thus, there is no difference in the microstructure due to heat treatment below 873 K. By contrast, in Fig. 5 (d), a lattice images and spot diffraction pattern were observed. So it was found that the DLC was crystalized by heat treatment at $1573 \mathrm{~K}$. However it was impossible to explain of decreases of Young's modulus and Vickers hardness by these results.

Accordingly, $s p^{3}$ fractions were calculated from EELS spectra. Figure 6 is comparison of carbon K-edge EELS spectra from as-deposited, heat treated DLS samples and graphite. The background model used was a standard power low, $A E^{-r}$, where $E$ is energy loss and $A$ and $r$ are fitting parameters. The spectrum of graphite was obtained from graphite powder (Nippon graphite CPB-S) 


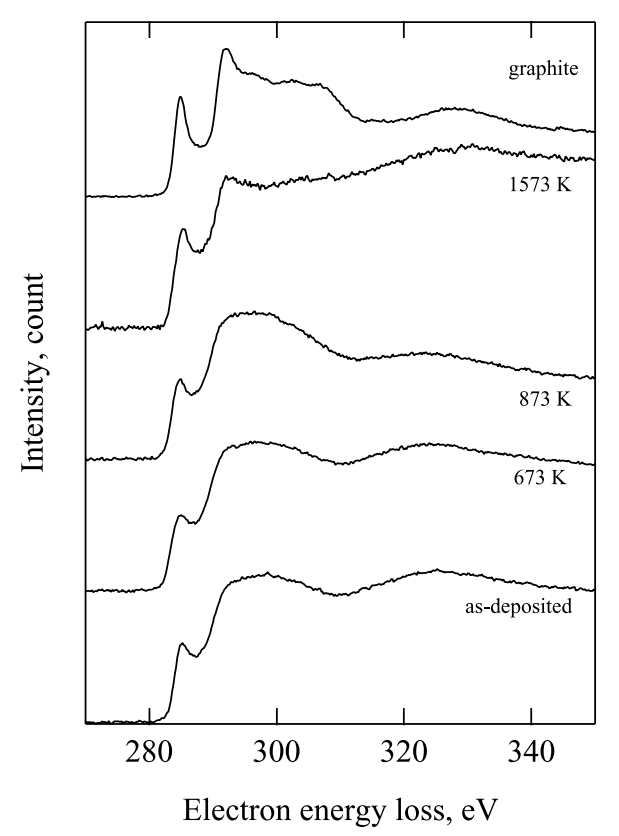

Fig. 6 Comparison of carbon K-edge EELS spectra for asdeposited and heat treated DLC samples. Graphite reference spectrum are also shown.

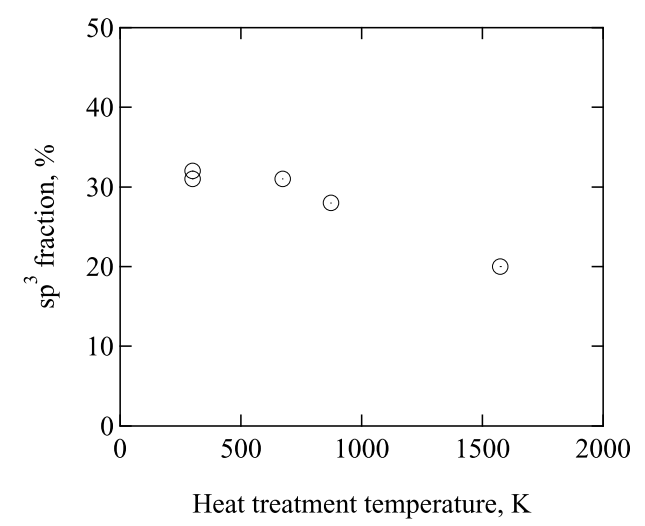

Fig. 7 Change of $s p^{3}$ fraction as a function of heat treatment temperature

with $99.99 \%$ purity. Common features include a peak at about $285 \mathrm{eV}$ and a broader peak at about $296 \mathrm{eV}$. The first peak is commonly corresponds to transmissions from $1 \mathrm{~s}$ to $\pi^{*}$ antibonding states, while the second is attributed to transmissions from $1 s$ to $\sigma$ antibonding states. As shown in Fig. 6, EELS spectra tend to vary similarly from spectrum of as-deposited to that of graphite with increasing heat treatment temperature.

By integrating the $\pi^{*}$ peak intensity relative to the $\sigma^{*}$ peak, the fraction of $s p^{3}$ bonds is quantified ${ }^{(8),(16),(17)}$. Figure 7 shows the change of the $s p^{3}$ fraction as a function of heat treatment temperature. From Fig. 7, it is found that the $s p^{3}$ fraction decreased with increasing heat treatment temperature. This result is consistent with Raman spectra analysis, which suggests increase of the $s p^{2}$ fraction. Therefore, it was indicated that the fraction of $s p^{3}$ corre- lated with the mechanical properties of the DLC. Consequently, the decrease of $s p^{3}$ fraction is one of the most influential factors, which decreases Young's modulus and Vickers hardness.

\section{Conclusion}

The influence of heat treatment on the mechanical and structural properties of DLC deposited by FIB-CVD was investigated. Young's modulus and Vickers hardness decreased with increasing heat treatment temperature. Analysis of Raman and EELS spectra indicated that the fraction of $s p^{3}$ decreased with increasing temperature. Therefore, it was shown that the fraction of $s p^{3}$ correlated with the mechanical properties of the DLC, and found that the decrease of $s p^{3}$ fraction was one of the factors, which decreases Young's modulus and Vickers hardness.

\section{Acknowledgment}

Parts of this work were conducted in Research Center for Nanoscience and Nanotechnology, Tokyo University of Science supported by "High-Tech Research Center" Project for Private Universities: matching fund subsidy from MEXT (Ministry of Education, Culture, Sports, Science and Technology), 2002-2006, and in AIST Nano-Processing Facility, supported by "Nanotechnology Support Project" of the Ministry of Education, Culture, Sports, Science and Technology (MEXT), Japan. The authors are grateful to T. Yagi, T. Hosho, S. Hyodo for assistance during this experiment.

\section{References}

( 1 ) Tsai, H. and Bogy, D.B., Characterization of Diamondlike Carbon Films and Their Application as Overcoats on Thin-Film Media for Magnetic Recording, J. Vac. Sci. Technol. A, Vol.5 (1987), pp.3287-3312.

(2) Singh, B., McClelland, D., Tamas III, F., Halon, B., Mesker, O. and Furst, D., Use of Black DiamondLike Carbon Films as a Contrast Enhancement Layer for Liquid-Crystal Displays, Appl. Phys. Lett., Vol.57 (1990), pp.2288-2290.

( 3 ) Gago, R., Jiménez, I., Albella, J., Climent-Font, A., Cáceres, D., Vergara, I., Banks, J.C., Doyle, B.L. and Terminello, L.J., Bonding and Hardness in Nonhydrogenated Carbon Films with Moderate $s p^{3}$ Content, J. Appl. Phys., Vol.87 (2000), pp.8174-8180.

( 4 ) Qian, F., Singh, R.K., Dutta, S.K. and Pronko, P.P., Laser Deposition of Diamondlike Carbon Films at High Intensities, Appl. Phys. Lett., Vol.67 (1995), pp.3120-3122.

( 5 ) Samano, E.C., Sato, G., Olivas, A. and Cota, L., DLC Thin Films Characterized by AES, XPS and EELS, Appli. Surf. Sci., Vol.202 (2002), pp.1-7.

( 6 ) Broitman, E., Hellgren, N., Czigány, Z., Twesten, R.D., Luning, J., Petrov, I., Hultman, L. and Holloway, B.C., Structural and Mechanical Properties of Diamond-Like Carbon Films Deposited by Direct Current Magnetron 
Sputtering, J. Vac. Sci. Technol. A, Vol.21 (2003), pp.851-859.

( 7 ) Nakazawa, H., Mikami, T., Enta, Y., Suemitsu, M. and Mashita, M., Structure, Chemical Bonding and These Thermal Stabilities of Diamond-Like Carbon (DLC) Films by RF Magnetron Sputtering, Jpn. J. Appli. Phys., Vol.42 (6B) (2003), pp.L676-L679.

( 8 ) Zhang, S., Zeng, X., Xie, H. and Hing, P., A Phenomenological Approach for the $I_{d} / I_{g}$ Ratio and $\mathrm{sp}^{3}$ Fraction of Magnetron Sputtered a-C Films, Suf. Coat. Technol., Vol.123 (2000), pp.256-260.

(9) Maharizi, M., Croitoru, N. and Seidman, A., Study of Influence of $\mathrm{Ar}$ on the Formation of Diamond-Like Bonds in Films Obtained from $\mathrm{CH}_{4}+\mathrm{Ar}$, RF Plasma Deposition, J. Non-Cryst. Solids, Vol.289 (2001), pp.221-227.

(10) Christiansen, S., Albrecht, M. and Strunk, H.P., Mechanical Properties and Microstructural Analysis of a Diamond-Like Carbon Coating on an Alumina/Glass Composite, J. Mater. Res., Vol.11 (1996), pp.19341942.

(11) Kimura, A., Kodama, H. and Suzuki, T., DiamondLike Carbon Films Deposited on Polyethylene Terephthalate, Substrates by Radio Frequency Plasma Chemical Vapor Deposition Method, J. Vac. Sci. Technol. A, Vol.21 (2003), pp.515-517.

(12) Matsui, S., Kaito, T., Fujita, J., Komuro, M., Kanda, K. and Haruyama, Y., Three-Dimensional Nanostructure Fabrication by Focused-Ion-Beam Chemical Vapor Deposition, J. Vac. Sci. Technol. B, Vol.18 (2000), pp.3181-3184.
(13) Kometani, R., Morita, T., Watanabe, K., Hoshino, T., Kondo, K., Kanda, K., Haruyama, Y., Kaito, T., Fujita, J., Ishida, M., Ochiai, Y. and Matsui, S., Nanomanipulator and Actuator Fabrication on Glass Capillary by Focused-Ion-Beam-Chemical Vapor Deposition, J. Vac. Sci. Technol. B, Vol.22 (2004), pp.257-263.

(14) Hoshino, T., Watanabe, K., Kometani, R., Kanda, T.M.K., Kaito, Y.H.T., Fujita, J., Ishida, M. and Matsui, Y.O.S., Development of Three-Dimensional PatternGenerating System for Focused-Ion-Beam ChemicalVapor Deposition, J. Vac. Sci. Technol. B, Vol.21 (2004), pp.2732-2736.

(15) Berger, S. and McKenzie, D., EELS Analysis of Vacuum Arc-Deposited Diamond-Like Films, Philosophical Magazine Letters, Vol.6 (1998), pp.285-290.

(16) McCulloch, D.G., Gerstner, E.G., McKenzie, D.R., Prawer, P. and Kalish, R., Ion Implantation in Tetrahedral Amorphous Carbon, Phys. Rev. B, Vol.52 (1995), pp.850-857.

(17) Kulik, J., Lifshitz, Y., Lempert, G.D., Rabalais, J.W. and Marton, D., Electron-Energy-Loss Spectroscopy of Mass-Selected Ion-Beam-Deposited Diamondlike Carbon, J. Appl. Phys., Vol.76 (1994), pp.5063-5069.

(18) Adamopoulos, G., Robertson, J., Morrison, A. and Godet, C., Hydrogen Content Estimation of Hydrogenated Amorphous Carbon by Visible Raman Spectroscopy, J. Appl. Phys., Vol.96 (2004), pp.6348-6352.

(19) Ferrari, A.C. and Robertson, J., Interpretation of Raman Spectra of Disordered and Amorphous Carbon, Phys. Rev. B, Vol.61 (2000), pp.14095-14106. 